\title{
Contribution Of Body Body Towards Basket Under Skills In Basketball Extracurricular Private Vocational School 01 Arga Makmur
}

\section{Kontribusi Kelentukan Tubuh Terhadap Keterampilan Under Basket Pada Ekstrakurikuler Bola Basket Smpn 01 Arga Makmur}

\author{
Rian Arindi Pradinata'), Mesterjon², Feby Elra \\ Perdima ${ }^{3)}$ \\ 1,2,3 Departemen Phsycal Education Study Program, Universitas \\ Dehasen Bengkulu, Bengkulu, Indonesia
}

Corresponding Author: :

feby.elra@unived.ac.id ${ }^{3)}$

How to Cite :

Arindi Pradinata, Rian, Mesterjon \& Elra Perdima, Feby. (2021). Contribution Of Body Body Towards Basket Under Skills In Basketball Extracurricular Private Vocational School 01 Arga Makmur. Hanoman Journal: Phsycal Education and Sport, 2 (1) 2021 page: 19-25. DOI: https://doi.org/10.37638/hanoman.2.1.19-25

ARTICLE HISTORY Received [21 May 2021] Revised [23 May 2021] Accepted [21 June 2021]

Kata Kunci :

Kelentukan Tubuh,

Keterampilan Underbasket,

ekstrakurikuler Bolabasket

Keywords :

Body Flexibility, Underbasket

Skills, Basketball

Extracurricular
This is an open access article under the $C C-B Y$-SA license

\section{ABSTRAK}

Penelitian ini bertujuan untuk mengetahui kontribusi kelentukan tubuh terhadap keterampilan under basket. Adapun rumusan masalah dalam penelitian ini adalah apakah ada hubungan kelentukan tubuh terhadap keterampilan under basket pada ekstrakurikuler bola basket SMPN 01 Arga Makmur? dan seberapa besar kontribusi kelentukan tubuh terhadap keterampilan under basket pada ekstrakurikuler bola basket SMPN 01 Arga Makmur? Penelitian ini dilakukan di SMP Negri 01 Argamakmur pada tahun 2020. Metode penelitian yang digunakan adalah metode korelasi dengan statistic product moment, penelitian ini secara objektif atau apa adanya dengan sampel 24 pemain basket yang diambil dengan teknik tota sampling. Adapun hasil data kelentukan tubuh terhadap keterampilan under basket rhitung= 0,97 > rtabel $=0,361$ maka Ho ditolak dan $\mathrm{Ha}$ diterima. Artinya terdapat hubungan yang berarti antara $X$ dan $Y$. Kontribusi kelentukan tubuh terhadap keterampilan under basket yaitu $K$ $=r 2 \times 100 \%=0,97 \% \times 100 \%$ yaitu 94,09\%. Sehingga dapat disimpulkan bahwa adanya hubungan yang kuat.

\section{ABSTRACT}

This study aims to determine the contribution of body flexibility to under basketball skills. The formulation of the problem in this study is whether there is a relationship between body flexibility and under basketball skills in basketball extracurricular activities at SMPN 01 Arga Makmur? and how big the contribution of body flexibility to under basketball skills in basketball extracurricular activities at SMPN 01 Arga Makmur? This research was conducted at SMP Negri 01 Argamakmur in 2020. The research method used is the correlation method with the statistical product moment, this research is objectively or as is with a sample of 24 basketball players taken by total sampling technique. The results of body flexibility data on under basketball skills $r$ count $=0.97>r$ table $=0.361$ then $\mathrm{Ho}$ is 
rejected and $\mathrm{Ha}$ is accepted. This means that there is a significant relationship between $X$ and $Y$. The contribution of body flexibility to under basketball skills is $K=r 2 \times 100 \%=0.97 \% \times 100 \%$, namely $94.09 \%$. So it can be concluded that there is a strong relationship.

\section{PENDAHULUAN}

Olahraga merupakan bagian dari aktivitas sehari-hari manusia yang berguna membentuk jasmani dan rohani yang sehat. Sampai saat ini olahraga di indonesia telah memberi kontribusi yang positif dan nyata bagi peningkatan kesehatan masyarakat. Selain itu olahraga turut berperan dalam meningkatkan prestasi bangsa dalam melaksanakan sistem pembangunan yang berkelanjutan. Sebagian besar masyarakat Indonesia menyadari bahwa pemeliharaan kesehatan sangat diperlukan selama manusia masih menghendaki hidup sehat jasmani dan rohani. Hal ini terbukti dengan berlomba-lombanya masyarakat Indonesia melakukan kegiatan olahraga dengan menyelenggarakan kompetisi yang bersifat daerah, nasional, maupun internasional serta pada hari-hari libur dilapangan yang memungkinkan untuk kegiatan olahraga.

Dalam perkembanganya, olahraga telah menjadi kebutuhan masyarakat untuk menjaga serta meningkatkan kondisifisik agar tetap bersemangat dalam melaksanakan aktifitas sehari-hari serta memiliki kemampuan berprestasi. Hal ini sesuai dengan tujuan khusus dari aktivitas berolahraga yang diyatakan oleh Muchtar dalam Indra (2009:1), yaitu kegiatan olahraga di Indonesia tidak hanya sekedar untuk kesegaran jasmani saja atau rekreasi, namun harus berfikir kearah peningkatan prestasi untuk dapat mengharumkan nama bangsa dan negara di gelanggaang internasional".

Perkembangan olahraga bola basket di indonesia awalnya dimulai dengan masuknya gelombang perantau dari Negara cina ke Indonesia pada tahun 1920-an. Sejak tahun 1930-an, walaupun belum resmi menjadi sebuah negara yang merdeka, beberapa kota di Indonesia sudah memiliki klub bola basket lokal. Saat penyelenggaraan Pekan Olahraga Nasional pertama (PON I) yang diadakan di Solo pada tahun 1948 permainan bola basket telah dimainkan untuk pertama kalinya ditingkat nasional. Kemudian Tiga tahun setelah itu, pada tanggal 23 Okober 1951, "Persatuan Basketball Seluruh Indonesia" di bentuk dan kemudian pada tahun 1955, karena adanya penyempurnaan nama sesuai dengan kaidah bahasa Indonesia maka organisasi bola basket tersebut berganti nama menjadi "Persatuan Bola Basket Seluruh Indonesia" (Perbasi). Perbasi mulai diterima menjadi anggota FIBA (the International Basketball Federation atau Federasi Bola Basket Internasional).

Setelah mengalami pasang surut selama hampir 30 tahun lamanya, dalam beberapa tahun terakhir ini olahraga permainan bola basket berkembang begitu pesat. Hal ini diawali oleh penyelenggaran Deteksi Basketball League (DBL) yang dikemas dengan sangat menarik sehingga mampu memberikan warna tersendiri 
dalam kompetisi tingkat pelajar di Indonesia, dan makin maraknya kompetisi tingkat pelajar ditiap-tiap daerah membuat makin tingginya tingkat pertandingan ditingkat pelajar Indonesia. Kemudian disusul dengan bangkitnya liga profesional basket putra yang pada awalnya dikenal dengan nama Kobatama yang sekarang menjadi National Basketball League (NBL) Indonesia dan juga liga profesional basket putri yang sekarang dikenal dengan Women's National Basketball League (WNBL). Namun, tidak lupa juga kompetisi regular dari Perbasi yang masih rutin diadakan, baik tingkat kejurnas kelompok umur, antar klub, antar pengprov, Libamanas, dan sebagainya kian membuat suasana kompetisi bola basket di Indonesia tetap terjaga kemeriahannya.

Menurut Adnan Fardi, (1999:24) Bola basket merupakan olahraga yang mengandung unsur-unsur gerakan yang kompleks dan beragam. Kemampuan seorang pemain untuk menampilkan gerakan sangat bergantung pada penguasaan teknik dasar yang menunjang permainan ini. Salah satu teknik dasar bola basket yang membutuhkan gerakan yang kompleks yaitu teknik dribble, permainan bola basket merupakan permainan sederhana yang dimainkan oleh dua regu dimana jumlah pemain dalam setiap regunya adalah lima orang pemain dan bertujuan untuk memperoleh nilai atau skor dengan memasukkan bola ke dalam keranjang lawan.

Kontribusi adalah sumbangan yang dapat diberikan oleh satu atau lebih variabel terhadap variabel lain, atau seberapa besar hubungan satu variabel atau lebih variabel memberikan sumbangan terhadap variabel lain. Besar kecilnya sumbangan tersebut dinyatakan dalam bentuk koefisien korelasi, yaitu dari angka 0 sampai dengan 1.

Kelentukan merupakan kemampuan tubuh untuk melakukan latihan dengan amplitudo gerakan yang besar atau luas persamaannya. Menurut Albertus Fenanlampir, (2015:131) bahwa "kelentukan merupakan komponen kesegaran jasmani yang merupakan kemampuan menggerakkan tubuh atau bagian-bagaian seluas mungkin tanpa terjadi ketegangan sendi dan cedera otot". Sedangkan menurut Davis (1989), kelentukan sesorang dipengaruhi oleh: tipe persendian, panjang istirahat otot, panjang istirahat ligamen dan kapsul sendi, bentuk tubuh, tempratur otot, jenis kelamin, usia, ketahanan kulit, dan bentuk tulang. .

Menurut John Oliver (2007:18) Tembakan dari bawah ring (under the basket shoot) sering digunakan ketika seorang pemain penyerang berada di dekat ring basket penerima sebuah umpan, merebut bola dari rebound, atau melakukan jumpstop setelah melakukan dribble-drive ke arah ring basket. Menurut Nuril Ahmadi dalam Sugiyanti (2013:12) "Shoot under basket merupakan tembakan dari posisi dibawah basket setelah melakukan dribel atau mendapatkan operan. Under basket merupakan salah satu teknik dasar dalam bola basket yang harus dikuasai dengan baik oleh setiap pemain karena teknik ini sangat mendukung terhadap teknik yang lain seperti lay up shoot, agar pemain dapat melakukan gerakan lay-up dengan baik, 
maka harus menguasai teknik under basket dengan baik pula serta biasanya dilakukan dari sudut 45 derajat dari setiap arah ke keranjang.

\section{METODE PENELITIAN}

Penelitian ini merupakan penelitian yang menggunakan uji korelasi (correlation research), yang bertujuan untuk mengetahui hubungan antara variabel bebas dan variabel terikat. Menurut Dewi Laelatul dalam Nanda Pratama (2017:17) "penelitian korelasional adalah penelitian yang bertujuan untuk mendeteksi sejauh mana variasi-variasi pada suatu faktor berhubungan dengan variasi pada satu atau lebih lain tanpa melakukan intervensi tertentu terhadap variasi variabel-variabel yang bersangkutan. Uji korelasi dilakukan untuk mengetahui hubungan antara kelentukan tubuh $(X)$ terhadap keterampilan under basket dalam olahraga bola basket $(\mathrm{Y})$ digunakan rumus korelasi. Teknik korelasi ini digunakan untuk mencari hubungan dan membuktikan hipotesis hubungan dua variabel bila data kedua variabel bentuk interval atau ratio.

\section{HASIL}

Dari hasil pengukuran kelentukan tubuh yang dilakukan terhadap pemain basket SMP N 01 arga makmur diperoleh skor tertinggi 22 dan skor terendah 11, berdasarkan data kelompok tersebut rata-rata hitung 12,56 dan simpangan baku (SD) 2,67. Distribusi kategori kelentukan tubuh dapat dilihat pada tabel berikut:

Dari data tabel disimpulkan bahwa dari 24 pemain sebanyak 1 pemain (4\%) memiliki kategori nilai 11-12, sebanyak 4 pemain (17\%) memiliki kategori nilai 13-14, sebanyak 6 pemain (25\%) memiliki kategori nilai 15-16, sebanyak 7 pemain (30\%) memiliki kategori nilai $17-18$, sebanyak 5 pemain (20\%) memiliki kategori nilai 5, dan sebanyak 1 pemain (4\%) memiliki kategori nilai 21-22.

Dari hasil pengukuran kelentukan tubuh yang dilakukan terhadap pemain basket SMP N 01 arga makmur diperoleh skor tertinggi 29 dan skor terendah 14, berdasarkan data kelompok tersebut rata-rata hitung 17 dan simpangan baku (SD) 3,58. Distribusi kategori kelincahan dapat dilihat pada tabel berikut:

Tabel 1. Distribusi Frekuensi Hasil Tes

\begin{tabular}{ccc}
\hline Hasil Tes & Frekuensi Absolut & Frekuensi Relatif (\%) \\
$14-16$ & 1 & 4 \\
$17-19$ & 3 & 13 \\
$20-22$ & 7 & 29 \\
$23-25$ & 9 & 37 \\
$26-28$ & 3 & 13 \\
$29-31$ & 1 & 4 \\
\hline Jumlah & $\mathbf{2 4}$ & $\mathbf{1 0 0}$ \\
\hline
\end{tabular}

Sumber: Data Diolah, 2020

22 | Arindi Pradinata, Rian, Mesterjon \& Elra Perdima, Feby. (2021). Contribution Of Body Body.... 
Dari tabel di atas disimpulkan bahwa sebanyak 1 pemain (4\%) memiliki kategori nilai 14-16, sebanyak 3 pemain (13\%) memiliki kategori nilai 17-19, sebanyak 7 pemain (29\%) memiliki kategori nilai 20-22, sebanyak 9 pemain (37\%) memiliki kategori nilai 23-25, sebanyak 3 pemain (13\%) memiliki kategori nilai $26-28$, dan sebanyak 1 pemain (4\%) memiliki kategori nilai 29-31.

Diketahui bahwa hipotesis yang diajukan dapat diterima, terdapat hubungan yang positif antara ketiga variabel yaitu:

R_hitung $=0,96>$ R_(tabel ) $=0,368$ sedangkan kontribusi variabel kelentukan tubuh dan keterampilan under basket sebesar 94,0\% dan 5,91 dipengaruhi oleh variabel lain. Dari hipotesis diatas disimpulkan bahwa terdapat kontribusi yang signifikan antara variabel bebas yaitu kelentukan tubuh $(X)$ dan variabel terikatnya yaitu keterampilan under basket $(\mathrm{Y})$. Untuk lebih jelasnya dapat dilihat pada tabel hasil rangkuman berikut:

Berdasarkan rangkuman hipotesis diatas dapat disimpulkan bahwa terdapat kontribusi yang signifikan antara variabel bebas yaitu kelentukan tubuh $(X)$ terhadap variabel terikatnya yaitu keterampilan under basket $(\mathrm{Y})$.

\section{PEMBAHASAN}

Berdasasarkan hasil penelitian yang telah di laksanakan dan di jelaskan pada pembahasan sebelumnya maka dapat di ambil suatu kesimpulan, bahwa telah di susun suatu instrument battery test keterampilan bola basket untuk Siswa Sekolah Dasar dan dapat di gunakan sebagai alat tes. Dikarenakan telah memenuhi syarat valid dan realiabel. Kontruksi Battery Test terdiri dari 3 bentuk instrument tes yaitu instrument tes dribbling, passing dan shooting. Dari hasil pengujian hipotesis antara kecepatan $(\mathrm{X})$ dengan keterampilan under Adapun penelitian yang relevan dengan penelitian ini adalah penelitian yang dilakukan oleh Raseb Prayoga (2017) dengan judul "Kontribusi Kekuatan Otot Lengan dan Kelentukan Tubuh terhadap Shooting Under Basket Pada Pemain Bola Basket Sma Negeri 01 Putri Hijau Kabupaten Bengkulu Utara". Adapun hasil data kekuatan otot lengan terhadap shooting under $r_{\text {hitung }}=0,98>r_{\text {tabel }}=0,349$ maka Ho ditolak dan Ha diterima, hasil data kelentukan tubuh terhadap shooting under $r_{\text {hitung }}=0,97>r_{\text {tabel }}=0,349$ maka Ho ditolakdan $\mathrm{Ha}$ diterima, hasil data kekuatan otot lengan dan kelentukan tubuh terhadap shooting under $r_{\text {hitung }}=0,94>r_{\text {tabel }}=0,349$ maka Ho ditolakdan Ha diterima, artinya terdapat hubungan yang berarti antaraX $\mathrm{X}_{1}, \mathrm{X}_{2}$ dan $\mathrm{Y}$. kontribusi kekuatan otot lengan dan kelentukan tubuh terhadap shoting under yaitu $\mathrm{K}=\mathrm{r}^{2} \times 100 \%=88,36 \%$. Sehingga dapat disimpulkan bahwa adanya hubungan yang kuat antara kekuatan otot lengan dan kelentukan tubuh terhadap shooting under basket. basket $(\mathrm{Y})$, diperoleh data sebesar 94,09\% dan 5,91 dipengaruhi oleh variabel lain. 


\section{KESIMPULAN DAN SARAN}

Kelentukan tubuh merupakan komponen penting untuk menunjang aktifitas fisik, khususnya dalam kegiatan berolahraga. Dalam olahraga bola basket, komponen kelentukan tubuh sangat berpengaruh terhadap keberhasilan seorang pemain dalam melakukan teknik-teknik dasar, khususnya teknik dasar under basket. Berdasarkan hasil penelitian yang dilakukan pada pemain basket SMP N 01 Argamakmur dengan melakukan pengambilan data, melakukan uji analisis yang terdiri dari: uji normalitas data, uji homogenitas, dan uji korelasi serta uji hipotesis maka dapat dikemukakan kesimpulan bahwa terdapat hubungan yang positif dan kontribusi yang signifikan seperti penjelasan di bawah ini:

Hubungan variabel kelentukan tubuh $(X)$ terhadap keeterampilan under basket $(Y)$ pemain basket SMP N 01 Argamakmur yang positif yaitu sebesar 0,97. Kontribusi kelentukan tubuh $(\mathrm{X})$ terhadap keterampilan under basket $(\mathrm{Y})$ pemain basket SMP N 01 Argamakmur yang positif yaitu sebesar 94,09\%.

Bagi pelatih bola basket agar dapat memberikan materi yang tepat dan menyusun program latihan khususnya untuk melatih ketepatan under basket yang didukung dengan kelentukan tubuh dan materi lainnya guna meningkatkan keterampilan under basket pemain basket SMP N 01 Argamakmur yang akan mendukung dalam mencetak poin

Bagi pemain/atlet, agar dapat mengembangkan kemampuan menguasai teknik-teknik basket khususnya teknik dasar under basket berdasarkan analisa yang telah diteliti pada penelitian ini.

Bagi dosen atau guru pendidikan jasmani kiranya dapat menganalisa variabel-variabel lain untuk meningkatkan kemampuan under basket dalam olahraga bola basket. Bagi peneliti yang ingin melanjutkan penelitian ini agar dapat menjadikan penelitian ini sebagai bahan informasi dan meneliti dengan populasi atau sampel yang berbeda dan dalam jumlah yang lebih banyak.

\section{DAFTAR PUSTAKA}

1. Adnan Fardi. (1999). Bola Basket Dasar. Padang: FIK UNP.

2. Albertus Fenanlampir. (2015) Tes Dan Pengukuran Dalam Olahraga. Yogyakarta: CV. Andi Offset.

3. Danny Kosasih. (2007). Fundamental Basketball. Jakarta: Karmedia.

4. Indra. (2009). Pengaruh Ballhandling Dalam Latihan bola Basket (Laporan hasil Penelitian). Padang: FIK UNP.

5. Mochamad Arifin. (2004). Metode Pelatihan Bola Basket Dasar. Surabaya: Diktat.

6. Nanda Pratama. (2017). Kontribusi Kecepatan Dan Kelincahan Terhadap Kemampuan Dribbling pemain SSB Harapan Bangsa Kabupaten Bengkulu Tengah. Bengkulu. UNIB. 
7. Nico Anggriawan. (2013). Analisis Tingkat Kesegaran Jasmani Ditinjau Dari Hasil Penilaian Pembelajaran Penjasorkes Pada Siswa SMA N 3 Bengkulu Tengah Tahunn Ajaran 2012/2013. Bengkulu: UNIB.

8. Sugiyanti. (2013). Perbedaan Keberhasilan Menembak Dengan Teknik Under The Basket Shoot Melalui Papan Pantul Dan Under The Basket Shoot Langsung Ke Ring Basket Siswa Putra Ekstrakurikuler SMP Negeri 5 Banguntapan. Yogyakarta. UNY.

9. Oliver, J. (2007).Dasar-Dasar Bola Basket. Bandung: Pakar Raya Pustaka.

10. Wissel, H (1996). Bola Basket. Jakarta: PT. Raja Grafindo Persada. 